\title{
Distribution of Alcohol Related ALDH2 Genotypes among Six Ethnic Groups of Nepal
}

\author{
Nanda Bahadur Singh ${ }^{1,2}$ \\ ${ }^{1}$ Unit of Human Biology and Genetics, Department of Biological Sciences \\ School of Science, University of Tokyo, Tokyo 113-0033, Japan \\ ${ }^{2}$ Address to Correspondence: Central Department of Zoology \\ Tribhuvan University, Kirtipur, Kathmandu, Nepal \\ Email:nanda_nepal@yahoo.com
}

\begin{abstract}
This paper attempts to detect alcohol related ALDH2 genotypes among six ethnic groups of Nepal. The ALDH2*2 allele is rarely found in Caucasians but readily detect in some 50 percent of the Orientals (Mongolians). Altogether 456 blood cum nail samples were collected from six ethnic groups and DNA extraction was carried out by NaI and Phenol-Chloroform methods and finally the samples were subjected to detect the distribution of ALDH2 genotype frequencies by the use of PCR-RFLP method. Allele frequencies were also calculated by the use of Hardy-Weinberg formula for analysis and interpretation. In the case of Nepalese ethnic populations, the ALDH2*2 allele frequency was found to range from the lowest $(1 \%)$ in the Raute to the highest $(8 \%)$ in the Gurung through the middle values found in the Chepang (2\%) and the Thakali (2.7\%), respectively. The prevalence of ALDH2*2 allele in the Dravidian Munda does not rule out its possible genetic admixture with either the Caucasoid or other ethnic groups. ALDH2*2 allele was totally absent in the Caucasoid Chidimar. Therefore, the ALDH2 gene allele frequency demonstrated ethnic distinction. The Chepang showed significant deviation from Hardy-Weinberg expectation.
\end{abstract}

Key words: ALDH $2 * 2$ allele frequency, alcoholism, Mongolians, Caucasians, genotypes, ethnic groups.

\section{INTRODUCTION}

Scientists have been working to unravel the complex relationship between genes and behavior to understand the excessive alcohol addiction and hope to find out better treatment. One of such genes is the enzyme acetaldehyde dehydrogenase (ALDH). Nearly all Caucasians have 2 major ALDH isoforms in the liver: a cytosolic ALDH1 and a mitochondrial ALDH2 (EC1.2.1.3). ALDH2, one of the two major isoforms, is of considerable interest because it is found in two polymorphic forms, the wild type of gene $(\mathrm{ALDH} 2 * 1)$ encodes the active enzyme whereas the mutant type gene $\left(\mathrm{ALDH} 2{ }^{*} 2\right)$ encodes the inactive enzyme. The ALDH $2 * 2$ allele is rarely found in Caucasians but readily detected in some $50 \%$ of the Orientals (Agarwal et al. 1981; Impraim et al. 1982; Oota et al. 2004; Chai et al. 2005) and is inherited as autosomal dominant. ALDH2 is involved in alcohol (ethanol) metabolism. During metabolism, alcohol is converted into acetaldehyde by a group of enzymes, which, in turns, is converted into the acetate. The acetate so produced by acetaldehyde oxidation is rapidly metabolized into carbon dioxide and water.

If the ALDH 2 gene is a mutant one $(\mathrm{ALDH} 2 * 2)$, the acetaldehyde will directly go to the blood as the toxic product will not be converted into carbon dioxide and water via acetate. It will be responsible for acute alcohol intoxication due to accumulation of acetaldehyde. Facial flushing, nausea, dizziness and tachycardia characterize this alcohol intoxication (Yokoyama et al. 2005). This kind of alcohol intolerance is due to the absence of the enzyme coded by ALDH2, frequently found in Mongoloid persons (Goedde et al. 1979 \& 1992). ALDH2 is another burning example of human coadaptation with another enzyme alcohol dehydrogenase $(\mathrm{ADH})$ to their exposed environment in relation to the particular diet (Ikuta et al. 1986; Luo et al. 2006). ALDH2 acts in detoxifying a wide variety of organic compounds, toxins and pollutants. Defects in ALDH leads to very rare Sjogren-Larsson syndrome in the ratio of 1:200,000 in humans (DeLaurenzi et al. 1996).

One of the most studied polymorphism is a single basepair mutation $(\mathrm{G} 1510 \mathrm{~A})$ in exon 12 of ALDH2 gene that causes an E487K substitution (ALDH2*2 allele) resulting in the inactivation of the enzyme. The ALDH2 locus was assigned to the distal part of the long arm of the chromosome 12 by means of a cDNA probe and Southern blot analysis (Hsu et al. 1985). Therefore, the most interesting polymorphism at nucleotide G1510A 
for ALDH $2 * 2$ allele was taken as a genetic marker to characterize its prevalent rate among Nepalese ethnic groups through the PCR-RFLP approach. The aim of the present study is to detect the distribution pattern of ALDH2 genotype frequencies among six ethnic groups of Nepal.

\section{MATERIALS AND METHODS}

Altogether 456 samples belonging to six Nepalese ethnic groups; namely Raute, Chidimar, Thakali, Gurung, Chepang and Munda were collected from different six places in Nepal (Fig.1) which were later subjected to genotyping for detecting the frequency of the ALDH2 gene by the use of PCR-RFLP approach (Table $1 \&$ Fig. 1). NaI and Phenol-Chloroform methods were implemented to extract DNA from blood as well as nails samples.

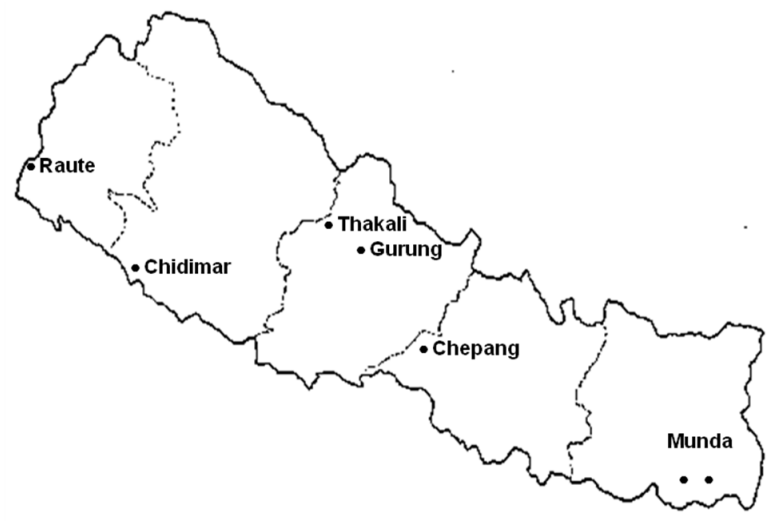

Fig. 1. Map and location of the indigenous populations studied in Nepal

PCR amplification was performed using an allele specific forward and reverse primer set: ALDH2U
(5'-CAAATTACAGGGTCAACTTGCT-3') and ALDH2D (5'- CCACACTCACAGTTTTCTCTT-3'), respectively. The underline base near the 3 ' end of the primer was mutant-specific substitution. Components of PCR reaction were PCR buffer I (Applied Biosystems, Japan), $1.5 \mathrm{mM} \mathrm{MgCl}, 0.2 \mathrm{mM}$ each dNTP, $0.4 \mathrm{pM} / \mathrm{ul}$ reverse and forward primer, and 0.03 unit/ul AmpliTaq Gold (ApplieBiosystems).

The conditions for the PCRs were an initial denaturation at $95^{\circ} \mathrm{C}$ for $9 \mathrm{~min}, 40$ cycles of $94^{\circ} \mathrm{C}$ for $30 \mathrm{sec}, 60^{\circ} \mathrm{C}$ for $30 \mathrm{sec}$ and $72^{\circ} \mathrm{C}$ for $1 \mathrm{~min}$ with additional extension at $72^{\circ} \mathrm{C}$ for $5 \mathrm{~min}$ in the last cycle. The PCR products were 135 bp single fragments for mutant allele and the subsequent Ksp632I digestion at $37^{\circ} \mathrm{C}$ for overnight cleaved the mutant type allele into $112 \mathrm{bp}$ and $23 \mathrm{bp}$ fragments. These fragments were visualized by $5 \%$ agarose gel electrophoresis followed by staining with ethidium bromide and photos were taken by the printgraph (Bioinstrument Atto, Japan). Finally, allele frequencies (ALDH $2 * 1 \&$ ALDH $2 * 2$ alleles) of the ALDH2 gene among Raute, Chidimar, Thakali, Gurung, Chepang, and Munda were calculated by the use of Hardy-Weinberg formula for analysis and interpretation (Table 1).

\section{RESULTS}

Fig. 2 reveals the genomic structure and Fig. 3 shows the band pattern of the PCR product after digesting with restriction enzyme, Ksp632I. Eliminating the Ksp632I restriction site from $112 \mathrm{bp}$ and $23 \mathrm{bp}$ fragments lengths, respectively, produced a single $135 \mathrm{bp}$ fragment. ALDH2 gene analysis shows genomic structure of the ALDH2 gene with 13 exons modified from Peterson et al. (1999) and designing an allele specific mutant primer set flanking point mutation at nucleotide 1510 changing from $\mathrm{G}$ to $\mathrm{A}$ in the exon 12.

(a)

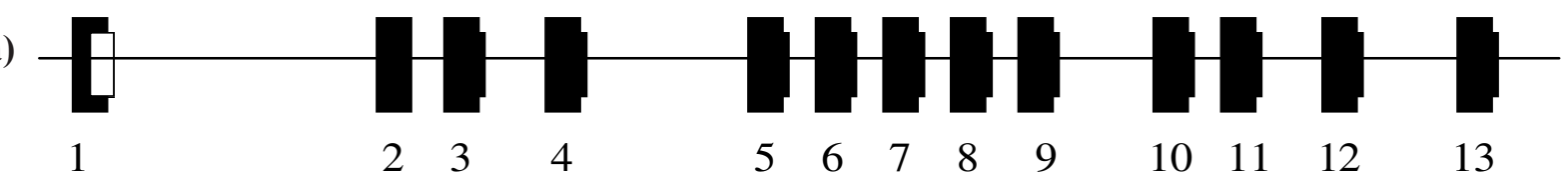

(b)

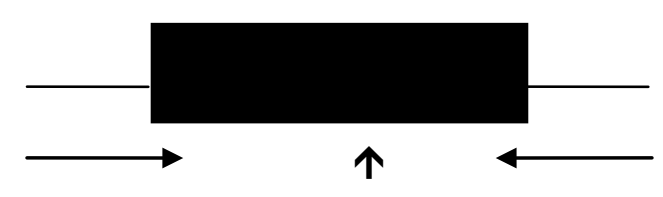

nt $1510 \mathrm{G} \rightarrow \mathrm{A}$

in the exon 12

Fig. 2. ALDH2 gene analysis: (a) Genomic structure of the ALDH2 gene with 13 exons modified from Peterson et al. (1999). (b) Designing an allele specific mutant primer set flanking point mutation at nucleotide 1510 changing from $G$ to $A$ in the exon 12 . 
1234

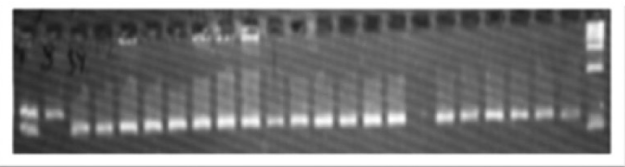

$135 \mathrm{bp}$

$112 \mathrm{bp}$

Fig. 3. PCR-RFLP products of the ALDH2 gene: PCR Products of ALDH2 exon 12 generated by PCR-RFLP digested with Ksp632I. A 135 bp mutant fragment was cleaved into two wild fragments of 112 and $23 \mathrm{bp}$. The fragments were visualized on $5 \%$ agarose gel electrophoresis followed by staining with ethidium bromide. Lanes 1\&2: heterozygous and mutant homozygous; lanes $3 \& 4$ : wild types.

Table 1 shows the allele frequencies of the ALDH2 gene in 6 Nepalese ethnic groups genotyped. The ALDH2 gene system is controlled by two alleles, ALDH $2 * 1 \&$ ALDH $2 * 2$, respectively. In the mutant type (inactive form), ALDH2*1 was replaced with ALDH2*2. The ALDH2 gene allele frequency demonstrated ethnic distinction. ALDH2*2 allele was totally absent in the Caucasoid Chidimar, but it was found in all Mongoloid ethnic groups, even in small percentage. This kind of genotype detections were not yet carried out among other Nepali ethnic groups, which is not possible to explore and to compare with other indigenous ethnic groups.

In the case of Nepalese Mongoloid ethnic populations, the $\mathrm{ALDH} 2 * 2$ allele frequency was found to range from the lowest (1\%) in the Raute to the highest (8\%) in the Gurung through the middle values found in the Chepang (2\%) and the Thakali $(2.7 \%)$, respectively. The prevalence of ALDH2*2 allele in the Dravidian Munda does not rule out its possible genetic admixture with either the Caucasoid or other ethnic groups. ALDH2*2 allele frequency among Nepalese Mongoloids was found to be consistent with range of Tibetan and Mongolians rather than other Chinese and Japanese populations (Chen et al. 1994). The ALDH2*2 allele was totally lacked in the individuals of the Caucasoid Chidimar. After analyzing genotype frequency data, the Chepang showed significant deviation from Hardy-Weinberg expectation. This genetic marker is distinctly found only among the Nepali Mongolians (Raute, Gurung, Thakali, and Chepang), but is totally absent in Nepali Caucasian population (Chidimar) and Dravidian Munda which is consistent to the other findings.

Table 1. Distribution of ALDH2 genotypes and frequency of the ALDH2*2 allele among six Nepalese indigenous populations

\begin{tabular}{|c|c|c|c|c|c|c|c|c|}
\hline \multirow[b]{2}{*}{ Population } & \multirow[b]{2}{*}{$\mathbf{n}$} & \multicolumn{3}{|c|}{ Genotype } & \multirow[b]{2}{*}{$P$ value } & \multirow{2}{*}{$\begin{array}{c}\begin{array}{c}\text { A L D H } 2 * 2 \\
\text { allele }\end{array} \\
\text { frequency } \\
\end{array}$} & \multirow[b]{2}{*}{ \pm} & \multirow[b]{2}{*}{ SE } \\
\hline & & $1 / 1$ & $1 / 2$ & $2 / 2$ & & & & \\
\hline Chepang & 72 & 70 & 1 & 1 & $<0.001$ & 0.021 & \pm & 0.012 \\
\hline Chidimar & 35 & 35 & 0 & 0 & - & 0.000 & \pm & 0.000 \\
\hline Gurung & 68 & 57 & 11 & 0 & $>0.05$ & 0.081 & \pm & 0.023 \\
\hline Munda & 88 & 88 & 0 & 0 & - & 0.000 & \pm & 0.000 \\
\hline Raute & 102 & 100 & 2 & 0 & $>0.05$ & 0.010 & \pm & 0.007 \\
\hline Thakali & 91 & 86 & 5 & 0 & $>0.05$ & 0.027 & \pm & 0.012 \\
\hline
\end{tabular}

$d y$-Weinberg equilibrium by means of $x^{2}$ test.

\section{DISCUSSION}

The present study is the first report on the distribution of genotypes and the allele frequency of the ALDH2 gene in Nepalese indigenous populations. The initial alcohol sensitivity, quite common in individuals of Mongoloid origin, might be due to a delayed oxidation of acetaldehyde rather than it's higher than normal production by atypical alcohol dehydrogenase (Goedde et al. 1979). The ALDH2*2 allele is frequent in, but confined to Asian individuals, and it appears to be a determinant against alcoholism. On the other hand, alcohol-drinking individuals having the ALDH2*2 genotype are at substantially high risk of developing esophageal and upper aero-digestive tract cancers, head and neck cancers, stomach cancer, colorectal cancer (nome@ galton.ucl.ac.uk, 2002; Ding et al. 2010; Matsuo et al. 2013).

The ALDH2*2 allele frequency found in Nepalese Mongoloids is much closer to Tibetans and Mongolians than to other Asian Mongoloids supports their proximal 
genealogical relationship, probably with Tibetans. The absence of the inactive form of the ALDH2 gene in the Caucasoid Chidimar is consistent with the previous reports on the Caucasoid and other non-Mongoloid populations (Chen et al. 1992; Goedde et al. 1992; Kim et al. 2008). Rare prevalence of ALDH2*2 allele in the Munda provides a clue of its genetic mixture in the past with other Caucasoid and other populations. In addition to this, the prevalence of the ALDH $2 * 2$ allele in Nepalese ethnic groups will protect them from the exposure to various alcohol-related diseases because of the protective nature of the ALDH2*2 allele against alcoholism (Hira et al. 2013) This kind of protective mechanism of the ALDH2*2 allele against has already been reported, especially in East Asians (Chen et al. 1999; Peng et al. 2007). The occurrence of the ALDH2*2 allele in the ethnic groups will lead to the genetic adaptation in relation to feeding system along with environments. The findings of the research are consistent to other researches carried out elsewhere (Hsu et al. 1985; Goedde et al. 1992; Chen et al. 1994; Peng et al. 2007; Kim et al. 2008; Ding et al. 2010; Matsuo et al. 2013).

\section{CONCLUSION}

The ALDH2*2 allele frequency found in Nepalese Mongoloids is much closer to Tibetans and Mongolians than to other Asian Mongoloids. The most important dimension of the prevalence of ALDH $2 * 2$ allele among Nepalese ethnic groups is to use the genotyping data as the tool to compare the various ethnic groups based on their ethnic differences. The consistent findings are observed in Nepali ALDH2 gene frequencies of six ethnic groups. ALDH $2 * 2$ is a genetic marker for Nepali Mongoloid population in order to distinguish it from Caucasians.

\section{ACKNOWLEDGEMENTS}

I am highly grateful to Professor Takafumi Ishida and his team for giving me the great opportunity of doing my research at Ishida Laboratory of Unit of Human Biology and Genetics, Department of Biological Sciences, School of Science, University of Tokyo in Japan. I am squarely indebted to the ethnic leaders and members of Raute, Chidimar, Thakali, Gurung, Chepand and Munda ethnic groups for their cooperation during my field visits.

\section{REFERENCES}

Agarwal, D.P,; Harada, S. and Goedde, H. W. 1981. Racial differences in biological sensitivity to ethanol: the role of alcohol dehydrogenase and aldehyde dehydrogenase isozymes. Alcoholism 5: 12-16.
Chai, Y.-G., Oh, D.-Y., Chung, E. K., Kim, G. S., Kim, L., Lee, Y.-S. and Choi, I.-G. 2005. Alcohol and aldehyde dehydrogenase polymorphisms in men with type I and type II alcoholism. Am. J. Psychiat. 162: 1003-1005.

Chen, S.H., Zhang, M.; and Scott, C.R.. 1992. Gene frequencies of alcohol dehydrogenase and aldehyde dehydrogenase 2 in northwest coast Amerindians. Hum Genet 89: 351-352.

Chen, S.H., Zhang, M.; Wang, N.S.; and Scott, C.R. 1994. Gene frequencies of alcohol dehydrogenase (ADH2) andaldehyde dehydrogenase 2 (ALDH2) in five Chinese minorities. Hum Genet 94: 571572.

DeLaurenzi, V., Rogers, G.R., Hamrock, D.L., Marekov, L.N., Steinert, P.M., Compton, J.G., Markekova, N. and Rizzo, W.B. 1996. Sjogren-Larsson syndrome is caused by mutations in the fatty acid aldehyde dehydrogenase gene. Nature Genetics 12:52-57.

Ding, J., Li, S., Cao, H., Wu, J., Gao, C., Liu, Y., Zhou, J., Chang, J. and Yao, G. 2010. Alcohol dehydrogenase- 2 and aldehyde dehydrogenase-2 genotypes, alcohol drinking and the risk for esophageal cancer in a Chinese population. J.Hum. Genet. 55: 97-102.

Gautam, R. andThapa-Magar, A. K. 1994. Tribal Ethnography of Nepal, Vol I and II. Book Faith India.

Goedde, H.W.; Agarwal, D.P.; Fritze, G.; MeierTackmann, D; Singh, S; Beckmann, G; Bhatia, K; Chen, LZ; Fang, B; Lisker, R.; Paik, Y.K.; Rothhammer, F.; Saha, N.; Segal, B.; Srivastava, L.M. and Czeizel, A. 1992. Distribution of ADH2 and ALDH2 genotypes in different populations. Hum. Genet. 88:344-346.

Goedde, H.W.; Harada, S. and Agarwal, D.P. 1979. Racial differences in alcohol sensitivity: a new hypothesis. Hum. Genet. 51: 331-334.

Hira A., Yabe H., Yoshida K., Okuno Y., Shiraishi Y., Chiba K., Tanaka H., Miyano S., Nakamura J., Kojima S., Ogawa S., Matsuo K., Takata M. and Yabe M. 2013. Variant ALDH2 is associated with accelerated progression of bone marrow failure in Japanese Fanconi anemia patients. Blood: 122(18):3206-9.

Hsu, L.C.; Bendel, R.E. and Yoshida, A. 1987. Direct detection of usual and atypical alleles on the human aldehyde dehydrogenase-2 (ALDH2) 
locus. Am. J. Hum. Genet. 41: 996-1001.

Hsu, L.C.; Yoshida, A.and Mohandas, T. 1985. Chromosomal assignment of the genes for human aldehyde dehydrogenase 1 (ALDH1) and aldehyde dehydrogenase 2 (ALDH2). Cytogenet. Cell Genet. 40: 656-657.

Ikuta, T.; Szeto, S. and Yoshida, A. 1986. Three human alcohol dehydrogenase subunits: cDNA structure and molecular and evolutionary divergence. Proc. Nat. Acad. Sci. 83: 634-638.

Impraim, C.; Wang, G, and Yoshida, A. 1982d. Structural mutation in a major human aldehyde dehydrogenase gene results in loss of enzyme activity. Am. J. Hum. Genet. 34: 837-841.

Ishida, T.; Takao, S.; Settheetham-Ishida, W. and Tiwawech, D. 2002. Prevalence of hepatitis B and $\mathrm{C}$ virus infection in rural ethnic populations of Northern Thailand. Journal of Clinical Virology 24:31-35.

Kim, D.-J., Choi, I.-G., Park, B. L., Lee, B.-C., Ham, B.J., Yoon, S., Bae, J. S., Cheong, H. S. and Shin, H. D. 2008. Major genetic components underlying alcoholism in Korean population. Hum. Molec. Genet. 17: 854-858.

Luo, X., Kranzler, H. R., Zuo, L., Wang, S., Schork, N. J.and Gelernter, J. 2006. Diplotype trend regression analysis of the ADH gene cluster and the ALDH2 gene: multiple significant associations with alcohol dependence. Am. J. Hum. Genet. 78: 973-987.
Matsuo, K., Oze I., Hosono, S, Ito H, Watanabe M, Ishioka K, Ito S,, Tajika M, Yatabe Y,, Niwa Y, Yamao K, Nakamura S, Tajima K, and Tanaka H. 2013. The aldehyde dehydrogenase 2 (ALDH2) Glu504Lys polymorphism interacts with alcohol drinking in the risk of stomach cancer. Carcinogenesis 34(7):1510-15.

Oota, H., Pakstis, A. J., Bonne-Tamir, B., Goldman, D., Grigorenko, E., Kajuna, S. L. B., Karoma, N. J., Kungulilo, S., Lu, R.-B., Odunsi, K., Okonofua, F., Zhukova, O. V., Kidd, J. R. and Kidd, K. K. 2004. The evolution and population genetics of the ALDH2 locus: random genetic drift, selection, and low levels of recombination. Ann. Hum. Genet. 68: 93-109.

Peng, G.S., Chen, Y.C., Tsao, T.P., Wang, M.F.and Yin, S.J. 2007. Pharmacokinetic and pharmacodynamic basis for partial protection against alcoholism in Asians, heterozygous for the variant ALDH2*2 gene allele. Pharmacogenet. Genomics 17: 845855.

Roychoudhury, A.K. and Nei, M. 1988. Human Polymorphic Genes: World Distribution. New York: Oxford Univ. Press (pub.).

Yokoyama, M., Yokoyama, A., Yokoyama, T., Funazu, K., Hamana, G., Kondo, S., Yamashita, T. and Nakamura, H. 2005. Hangover susceptibility in relation to aldehyde dehydrogenase-2 genotype, alcohol flushing and mean corpuscular volume in Japanese workers. Alcohol Clin. Exp. Res. 29: 1165-1171. 